\title{
Compressive behaviour of wheat from confined uniaxial compression tests**
}

\author{
Changnv Zeng ${ }^{1}$ and Yuke Wang ${ }^{2,3,4 *}$ \\ ${ }^{1}$ College of Civil Engineering and Architecture, Henan University of Technology, \\ ${ }^{2}$ College of Water Conservancy and Environmental Engineering, Zhengzhou University, \\ ${ }^{3}$ National Local Joint Engineering Laboratory of Major Infrastructure Testing and Rehabilitation Technology, \\ ${ }^{4}$ Collaborative Innovation Center of Water Conservancy and Transportation Infrastructure Safety, Henan Province; \\ Zhengzhou 450001, China
}

Received November 21, 2018; accepted May 22, 2019

\begin{abstract}
The present paper focuses on the compression characteristics of granular wheat stored in silos. The confined uniaxial compression tests of wheat were performed to investigate the compression behaviour of granular wheat. The effects of different loading paths and different maximum loading levels on the compression index and elastic moduli were analysed. The compression curves for each specimen were obtained from the test results. It was observed that nearly $80 \%$ of the total deformation occurred in the virgin loading stage. The compression index and elastic moduli were determined, which indicates that both the parameter compression index and elastic moduli correlate with the loading path.

Keywords: wheat, compression test, elastic moduli, compression index
\end{abstract}

\section{INTRODUCTION}

Wheat is one of the major commercial crops in many countries around the world, it forms approximately $21 \%$ of the world's food (Ortiz et al., 2008). China is the largest wheat producer in the world. Due to the huge population of China, a large portion of the wheat is stored for 3-5 years,

\footnotetext{
*Corresponding author e-mail: ykewang@163.com

**This work was substantially supported by the Plan for Youth Core Teachers of Henan University of Technology (2015004), the Key Scientific Research Project Plan of High School in Henan Province (19A560009), the Provincial Key Laboratory for Grain and Oil Storage Facility \& Safety, Henan University of Technology (2016KF-B03), Special scientific research project in grain public welfare industry (201513001), 2015-2019.
}

which is much longer than that in other developed countries (Li et al., 2011). Therefore, the safe storage of wheat in silos is of great concern to the Chinese government and experts.

During storage wheat is subjected to various forces, such as gravity loading, internal friction and the force due to contact with the walls of silos (Thompson et al., 1983; Moya et al., 2002; Moya et al., 2006; Moya et al., 2013; Liu et al., 2014; Zhang et al., 2003; Zhang et al., 2014). The storage conditions of grains are always different from the theoretically predicted conditions. For example, the bulk density or void ratio of wheat will change due to compaction. During every storage period, wheat may be removed from the silos or added to them. Thus, the wheat will be compressed and recompressed, which may result in changes to the silo pressure, grain flow and the grain mass in storage bins (Madiouli et al., 2012; Ramírez et al., 2010). The compressive behaviour of the wheat during storage is a fundamental mechanical property of the cereal grain, hence, it should be investigated. However, there is a lack of knowledge concerning the compressive behaviour of granular wheat, especially the compressive and re-compressive behaviour during long-term storage, which is a part of China's grain storage policy.

(C) 2019 Institute of Agrophysics, Polish Academy of Sciences 
At present, many researchers are investigating the properties of grain focusing on the internal frictional angle of the grain as well as its bulk density, and the friction angle between concrete or steel (Fitzpatrick et al., 2004; Horabik et al., 2002; Ramírez et al., 2009; Ramírez et al., 2010; Zhao et al., 2013; Horabik et al., 2014; Boac et al., 2015; Gao et al., 2018), which are also recommended in many official recommendations for the design of silos. A knowledge of the compression characteristics of wheat is important in understanding the mechanical properties of the wheat. According to a literature search, confined uniaxial compression tests and oedometer tests were widely used to determine the compression characteristics of soils and other granular materials (Thompson et al.,1983; Sawicki et al.,1998; Molenda et al., 2002; Stasiak, 2003; Stasiak et al., 2007; Monkul et al., 2006; Ramírez et al., 2009; Ramírez et al., 2010; Stasiak et al., 2010; Keller et al., 2011; Turner et al., 2016; Xiao et al., 2017; Yigit, 2018; Wang et al., 2019).

Moreover, an understanding of the compaction characteristics of materials relies on models, and there are two types of models to describe the compaction of materials. The first type may be illustrated by the relationship between the normal compressive stress $\left(\sigma_{z}\right)$ and the void ratio $(e)$ or specific volume $(v=1+e)$. The second type is expressed by normal compressive stress $\left(\sigma_{z}\right)$ against strain $\left(\varepsilon_{z}\right)$. For the first type, the compression index $\left(C_{c}\right)$ and preconsolidation stress $\left(\sigma_{p}^{\prime}\right)$ are the two defining features of the compression characteristic, which are usually based on the $e-\log \sigma_{z}$ space. While for the second type of stressstrain model, the elastic constants should be determined. The geotechnical engineering literature is replete with the compaction behaviour of different type soils (Akbas et al., 2009; Jiang et al., 2014; An et al., 2015; Wang et al., 2016; Wang et al., 2018). In contrast to soils, wheat particles have properties, which differ significantly from those of the corresponding soil particles. This variations may result in differences to their compression behaviour.

Based on the analysis above, in this study, the confined uniaxial compression test was used to investigate the compression characteristics of winter wheat from Henan province, where most of the $70 \%$ of the wheat products from China were produced. The compression curves for each specimen were obtained from the test results, and the compression index $\left(C_{\mathrm{c}}\right)$ and elastic moduli $(E)$ were determined. The effects of different loading paths and different maximum loading levels on the compression index and elastic moduli were analysed and discussed in detail.

\section{MATERIALS AND METHODOLOGY}

The winter wheat used was uniformly graded and grown in Henan Province. In this paper, the average particle sphere was determined by two parameters. The average major axis (named as $a$ ) and minor axis (named as the ave- rage of $b_{1}$ and $b_{2}$ ) of twenty grains was 6.08 and $3.28 \mathrm{~mm}$, respectively (Fig. 1). The grade curve of wheat used in this paper was demonstrated in Fig. 2 by a sieve analysis method. It was found that the aggregate of wheat particles is very uniform.

The wet basis moisture content of wheat is $11.5 \%$, which was obtained by drying it in an oven at temperatures of $105-110^{\circ} \mathrm{C}$. The specific gravity for the wheat is 1.31 , which was obtained using the pycnometer method at $22 \pm 5^{\circ} \mathrm{C}$ according to the code of $\mathrm{GB} / \mathrm{T} 5518-2008$ in China. The specific gravity was calculated using Eq. (1):

$$
G_{s}=\frac{m_{1}}{m_{2}}=\frac{m_{1}}{V},
$$

where: $G_{s}$ is the specific gravity; $m_{1}$ is the weight of the wheat; $m_{2}$ is the weight of water with the same volume of the wheat at $22 \pm 5^{\circ} \mathrm{C} ; \mathrm{V}$ is the volume of the wheat. In addition, the bulk density was used to describe the samples in the test mould. The bulk density of wheat in this paper was calculated using Eq. (2):

$$
\rho=\frac{m}{V},
$$

where $\rho$ is the bulk density of bulk wheat; $m$ is the weight of the sample in the compression mould; $V$ is the volume of the compression mould. In these tests, the bulk densities of the wheat ranged from 8.27 to $8.74 \mathrm{kN} \mathrm{m}^{-3}$, which is usually stored in silos.

In order to investigate the compressive behaviour of granular wheat, confined uniaxial compression tests were carried out in this study. During this test, lateral deformation of the sample was prevented. The apparatus consisted of a cylindrical mould, loading systems and measurements. A cylinder mould was used with $100 \mathrm{~mm}$ in diameter and
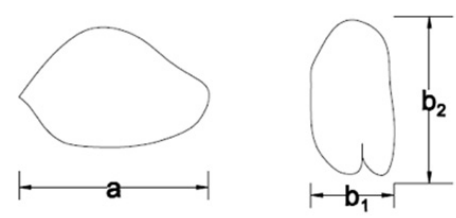

Fig. 1. Size of wheat grain.

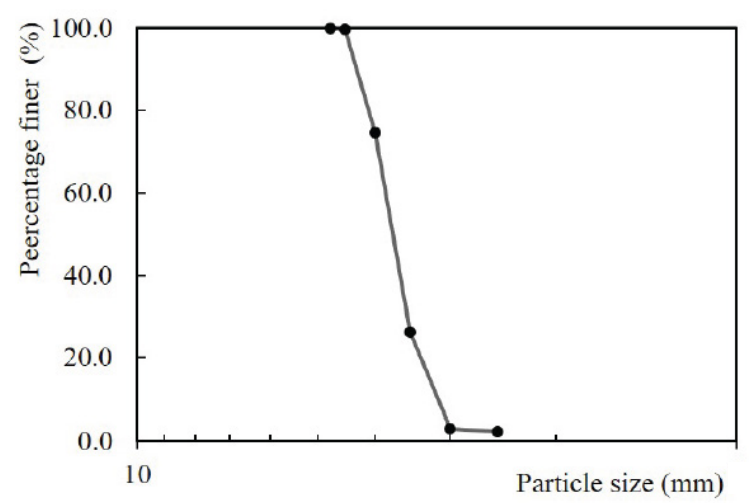

Fig. 2. Grade curve of wheat grain. 
200 in depth. The vertical load was applied by a lever with weights. The vertical displacement was measured by transducers and recorded automatically by a computer-controlled data acquisition system.

The testing method referred to the Trade Standard of P.R. China SL237 (1999) and also the literature (Molenda et al., 2006; Sawicki et al., 1998). With these tests, the loading and unloading stress paths were considered to derive the compression index as well as the elastic moduli. The tests are detailed in Table 1.

During testing, the wheat was poured into a cylindrical mould without vibration or any other tamping and having a certain value of specific weight. The test sample was $30 \mathrm{~mm}$ in height and $100 \mathrm{~mm}$ in diameter. Six sequential vertical stresses were applied on the top surface of the specimen step by step, including $12.5,25,50,100,200,400$, and $600 \mathrm{kPa}$, respectively. Each stress stage was applied for at least 120 min until the compressive deformation was less than $0.005 \mathrm{~mm} \mathrm{~h}^{-1}$ under the loading of the last step and the displacement (accuracy $0.001 \mathrm{~mm}$ ) was recorded.

After obtaining a recorded displacement $(d h)$ at the end of each loading interval, the void ratio $(e)$ of the specimen under each compression stress may be calculated using Eq. (3):

$$
e=e_{o}-\left(1+e_{o}\right) \frac{d h}{h_{0}},
$$

where: $e_{o}$ is the initial void ratio of the specimen, $e$ is the void ratio of the specimen under a vertical stress, $d h$ is the recorded displacement of the specimen under the vertical stress, and $h_{0}$ is the initial height of the specimen.

The initial void ratio is given by Eq. (4):

$$
e_{o}=\frac{\rho_{s}}{\rho_{d}}-1 \text {, }
$$

where: $\rho_{s}$ is the particle density with the same value of specific gravity mentioned in section 2.1 , and $\rho_{d}$ is the initial dry bulk density of wheat used in this paper.

\section{EXPERIMENTAL RESULTS}

The compression curve, which may be used to illustrate the compression characteristic, was constructed for each specimen. This curve graphically represents the relationship between the applied stress and the void ratio or vertical strain of each specimen.

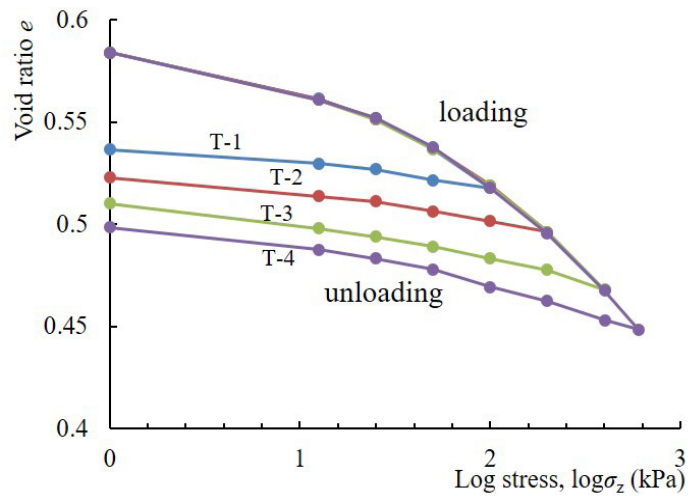

Fig. 3. Relationship between void ratio and applied stress.

The compression curves were presented for the tested materials with four different maximum stress levels (Fig. 3). Each different sample was loaded to a different maximum stress level and then unloaded to zero. It may be clearly seen that the void ratio decreased quickly when low stress levels were applied, and then gradually decreased until it decreased along a straight line. It may be observed that the compression curves for the different maximum stress levels, are nearly the same. The four unloading curves are nearly parallel to each other, which means that the maximum stress level has little effect on the loading and unloading process.

Basic experimental work was also conducted on granular wheat. The samples of investigated materials were subjected to a prescribed program of vertical loading and unloading. The experimental results were interpreted in terms of the vertical stress and vertical strain measured during the tests. During loading a curvilinear path OA is followed. The unloading path may be approximated by two linear sectors $\mathrm{AB}$ and $\mathrm{BC}$ (Fig. 4 a), and there is a residual strain present in the granular wheat. Though the classical representation of the unloading paths is usually nonlinear, a bilinear approximation is sufficiently good as proposed by Sawicki et al. (1998) for practical use. The bilinear approximation of unloading is the key to the method of determining the elastic moduli of agricultural granular materials.

Different maximum loading values of 100, 200, 400, and $600 \mathrm{kPa}$, respectively, are considered in the compressive behaviour of four samples (Fig. $4 \mathrm{~b}$ ). It is obvious that

Table 1. Test loading and unloading details

\begin{tabular}{lccl}
\hline Case No. & $\begin{array}{c}\text { Bulk density } \\
\left(\mathrm{kN} \mathrm{m}^{-3}\right)\end{array}$ & $\begin{array}{c}\text { Maximum loading } \\
\text { stress }(\mathrm{kPa})\end{array}$ & Series loading and unloading stress $(\mathrm{kPa})$ \\
\hline $\mathrm{T}-1$ & 8.27 & 100 & $0,12.5,25,50,100,50,25,12.5,0$ \\
$\mathrm{~T}-2$ & 8.27 & 200 & $0,12.5,25,50,100,200,100,50,25,12.5,0$ \\
$\mathrm{~T}-3$ & 8.27 & 400 & $0,12.5,25,50,100,200,400,200,100,50,25,12.5,0$ \\
$\mathrm{~T}-4$ & $8.27-8.74$ & 600 & $0,12.5,25,50,100,200,400,600,400,200,100,50,25,12.5,0$ \\
T-5-1 to T-5-10 & 8.27 & 600 & $\begin{array}{l}0,12.5,25,50,100,200,400,600,400,200,100,50,25,12.5,0, \\
\text { respectively and for ten cycles }\end{array}$ \\
\hline
\end{tabular}



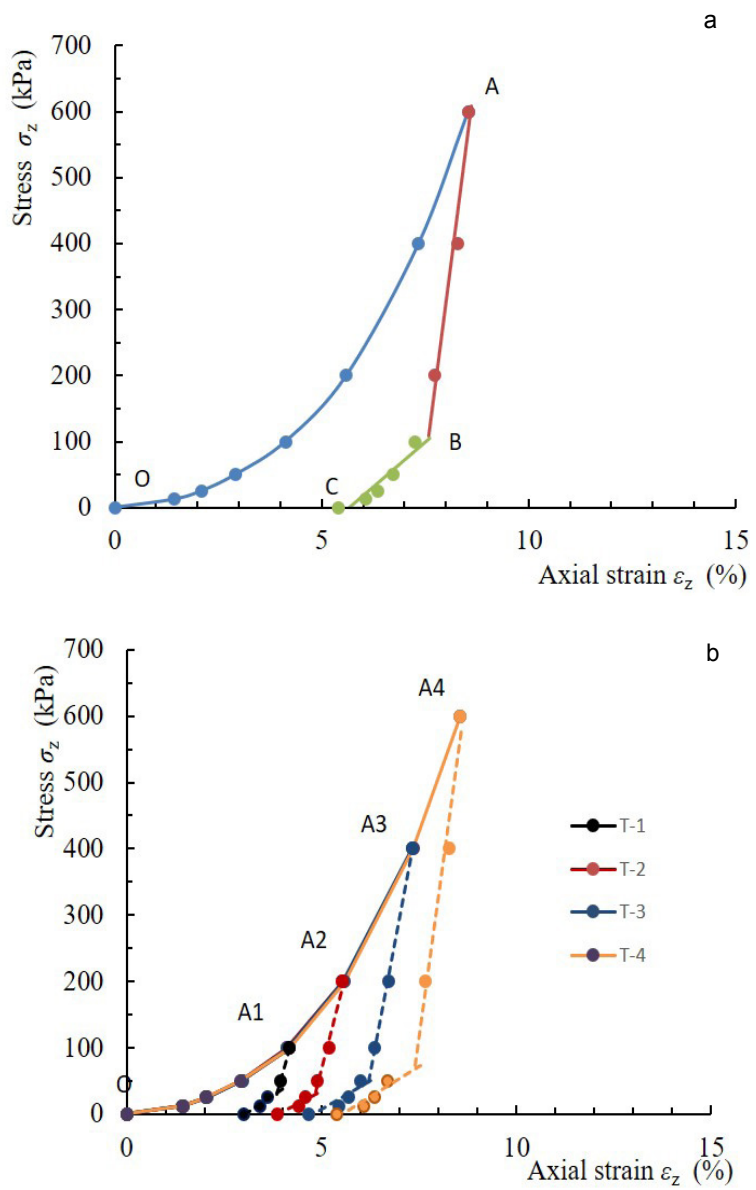

Fig. 4. Common loading curve for the wheat: $a-T-4$ result, $b-T-1$ to $\mathrm{T}-4$ test result.

stress-strain curves with different maximum vertical stress levels display a similar trend during loading. The bilinear approximation of unloading is certified by each curve, which means that different slopes of unloading curves occur and they are independent of the maximum stress level. In order to illustrate the effect of loading and unloading on the compression characteristics of wheat, ten cycles of loading and unloading were conducted for a wheat sample. It was found that the effect of the loading cycles is very significant especially for the virgin loading stage (Fig. 5a). An important feature is that the virgin loading curve is steeper because the material is compacted at a rapid rate in this cycle. Nearly $80 \%$ of the total deformation occurred in the initial loading stage (Fig. 5a, c). The subsequent loading and unloading cycles of the following stages are qualitatively similar to each other (Fig. 5a, b).

The stress-strain curves of ten cycles of loading and unloading processes are also examined (Fig. 6 and Fig. 7). Subsequent loading and unloading cycles are qualitatively similar, and different from the initial cycle. An important feature is that the subsequent loading curves are not so steep because the material is being forcefully compacted at the initial stage. A larger residual strain occurs during
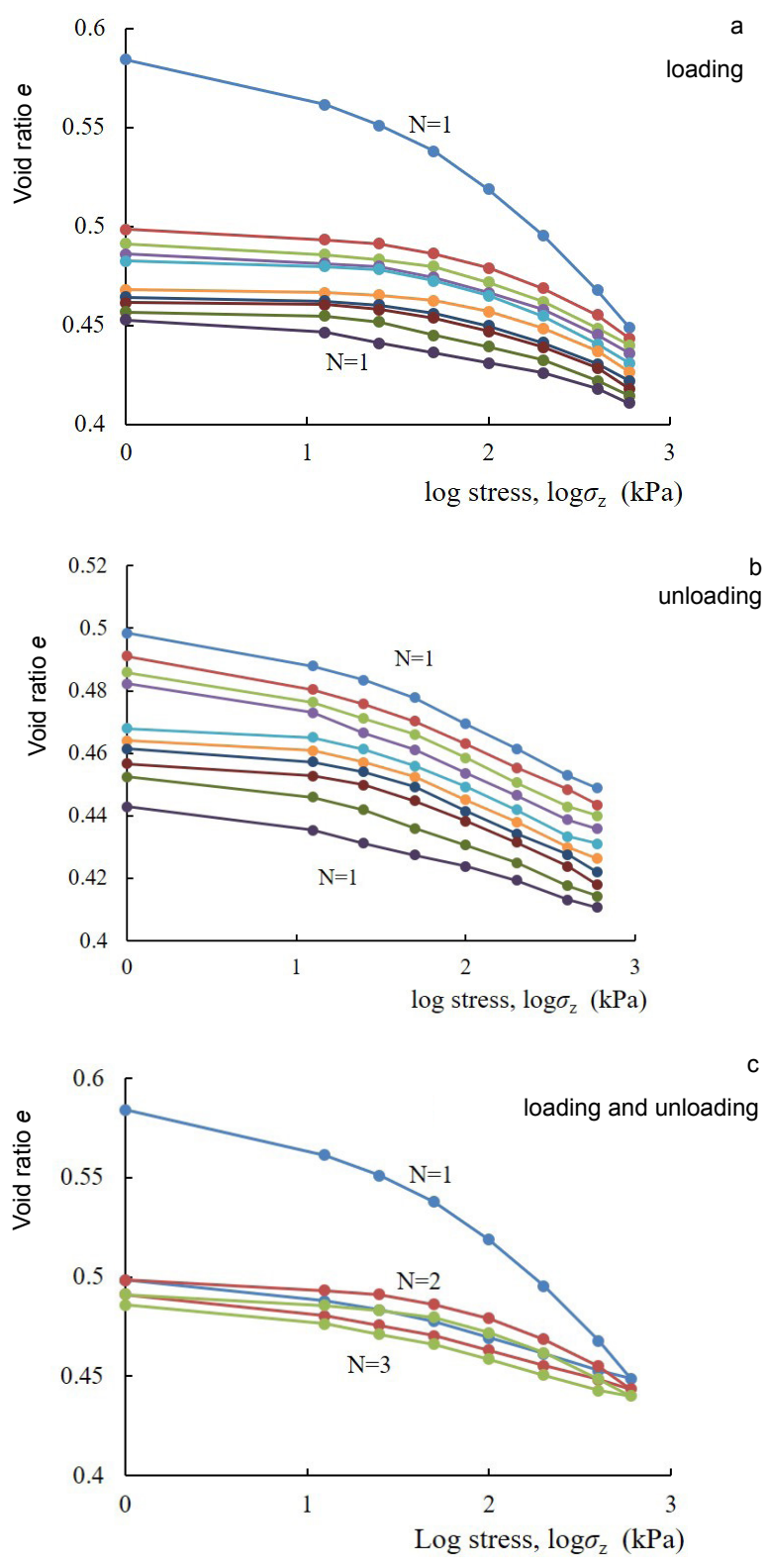

Fig. 5. Relationship between the applied stress and void ratio $e$ : $\mathrm{a}$ - loading for ten cycles, $\mathrm{b}$ - unloading for ten cycles, $\mathrm{c}$ - loading and unloading for the first three cycles.

the first loading cycle. When the subsequent loads are applied, weaker plastic strains occur. An interesting empirical observation is that the unloading curves corresponding to subsequent cycles are also similar from a qualitative point of view.

A common unloading curve is obtained by shifting all of the unloading curves (Fig. 6) to the origin of the coordinate system (Fig. 7). The similar characteristics of unloading in each cycle suggest that the sample behaves elastically during the unloading, at least during the virgin unloading stage. It should be noted that the reaction of the material to applied loads is elastic when permanent (plastic) strains are not developed. Such a situation appears in the virgin stage 


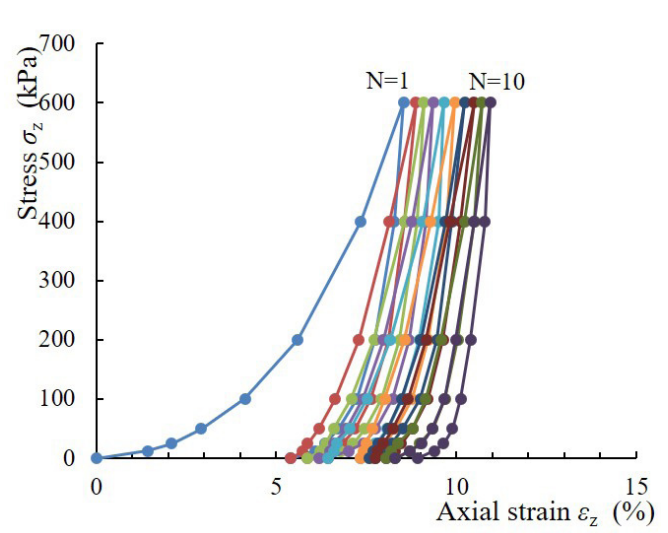

Fig. 6. Ten subsequent cycles of loading and unloading of wheat.

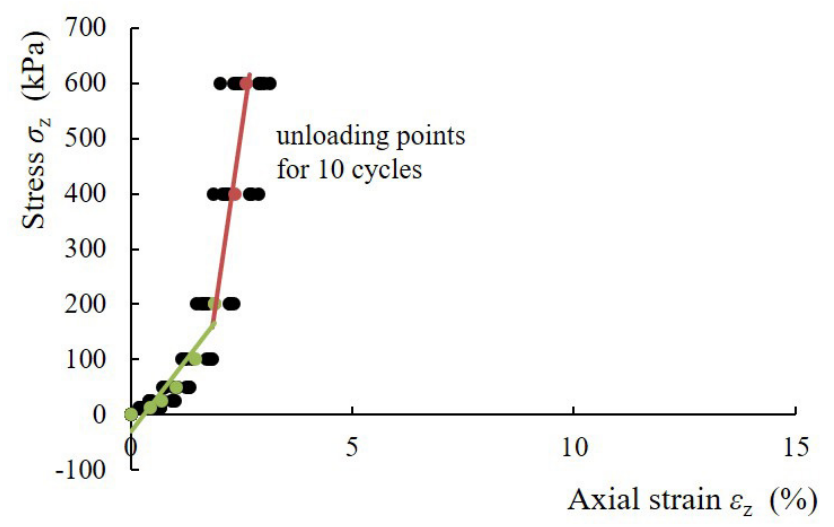

Fig. 7. Common unloading curve of wheat.

of unloading under uniaxial compression conditions where the same strain is recovered during each cycle, for the same unloading conditions in the stress path (at least within the accuracy of the theoretical approximation of the empirical data). Subsequent reloading induces both elastic and plastic (compaction) strains, which leads to hysteresis behaviour (Fig. 6).

Three curves, which were a fourth-order polynomial curve used by Arvidsson and Keller (2004) and two sigmoidal curves suggested by Gregory et al. (2006), were usually used to describe the compression characteristics. In the present study, the logistic curve is used to fit the experimental data, as given by Gregory et al. (2006):

$$
e=a+c\{1+\exp [b(\log \sigma-m)]\}^{-1}
$$

where: $a, b, c$ and $m$ are the adjustable parameters; log is the logarithm with base 10; and $\sigma$ is the applied compression stress.

In the compression curve (Fig. 8), which relates the logarithm (base 10) of applied stress to the void ratio, the slope of the virgin compression curve is commonly called the compression index $\left(C_{\mathrm{c}}\right)$. The parameter $C_{\mathrm{c}}$ is usually used to estimate the general resistance to compression (Cetin, 2004; Mohammadzadeh et al., 2014). When the

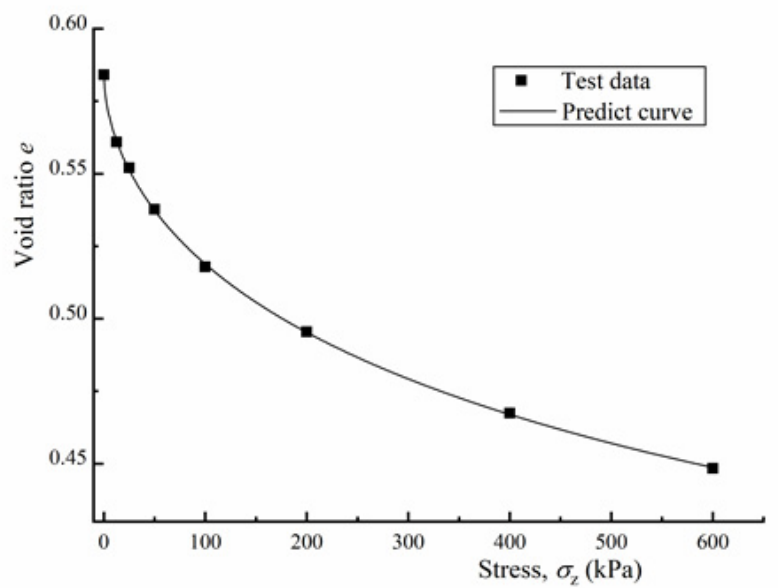

Fig. 8. Comparison between the measured and predicted values of a typical compression curve (T4 with bulk density of $8.27 \mathrm{kN} \mathrm{m}^{-3}$ ). experimental compression curve is fitted or described by the logistic equation (Eq. (5)), the value of parameter $C_{\mathrm{c}}$ is then readily estimated as follows (Gregory et al., 2006):

$$
C_{c}=\frac{b c}{4}
$$

It should be noted that the reaction of the material to applied loads is elastic when permanent (plastic) strains are not developed. Such a situation appears in the first stage of unloading under oedometric conditions, which was originally proposed by Sawicki et al. (1998). In the present study, the method based on the concept mentioned above was used to obtain the modulus constants of granular wheat. The theoretical equation may be expressed as follows:

$$
\begin{gathered}
E^{*}=\frac{\sigma_{z}^{A}-\sigma_{Z}^{B}}{\varepsilon_{z}^{A}-\varepsilon_{z}^{B}}, \\
E=E^{*}\left[1-\frac{2 v^{2}}{1-v}\right],
\end{gathered}
$$

where: $v$ denotes Poisson's ratio, $E^{*}$ denotes the slope of the unloading sector $\mathrm{AB}$ in the $\sigma_{z}, \varepsilon_{z}$ space, $E$ denotes the elastic modulus.

\section{DISCUSSION}

The logistic equation (Eq. (5)) fitted the experimental data well. The values of the adjustable parameters for the T4 value tested in the study were as follows: $a=0.241-0.390$, $b=1.186-2.185, c=0.080-0.337$, and $m=2.003-3.624$. In the equation, the parameter $a$ value corresponds approximately to the lower or final void ratio $e_{\min }$, i.e. the asymptote of Eq. (5) at the limit of the compression stress as $\sigma \rightarrow \infty$, while the $(a+c)$ value is the upper or initial void ratio $\left(e_{0}\right)$ (Gregory et al., 2006).

The values of the compression index $\left(C_{\mathrm{c}}\right)$ were derived from the fitted compression curve using Eq. (6) (Table 2). For ten cycles of loading tests (case T-5-1 to T-5-10), the values of the compression index are in the range of $0.034-$ 0.111 . The maximum compression index was 0.111 , which 
Table 2. Compression index

\begin{tabular}{cccc}
\hline $\begin{array}{c}\text { Case } \\
\text { No. }\end{array}$ & $\begin{array}{c}\text { Bulk density } \\
\left(\mathrm{kN} \mathrm{m}^{-3}\right)\end{array}$ & $\begin{array}{c}\text { Maximum loading } \\
\text { stress }(\mathrm{kPa})\end{array}$ & $\begin{array}{c}\text { Compression } \\
\text { index } C_{\mathrm{c}}\end{array}$ \\
\hline $\mathrm{T}-1$ & 8.27 & 100 & 0.197 \\
$\mathrm{~T}-2$ & 8.27 & 200 & 0.099 \\
$\mathrm{~T}-3$ & 8.27 & 400 & 0.107 \\
$\mathrm{~T}-4$ & $8.27-8.74$ & 600 & 0.110 \\
$\mathrm{~T}-5-1$ & 8.27 & 600 & 0.111 \\
$\mathrm{~T}-5-2$ & 8.27 & 600 & 0.099 \\
$\mathrm{~T}-5-3$ & 8.27 & 600 & 0.055 \\
$\mathrm{~T}-5-4$ & 8.27 & 600 & 0.052 \\
$\mathrm{~T}-5-5$ & 8.27 & 600 & 0.051 \\
$\mathrm{~T}-5-6$ & 8.27 & 600 & 0.067 \\
$\mathrm{~T}-5-7$ & 8.27 & 600 & 0.043 \\
$\mathrm{~T}-5-8$ & 8.27 & 600 & 0.053 \\
$\mathrm{~T}-5-9$ & 8.27 & 600 & 0.036 \\
$\mathrm{~T}-5-10$ & 8.27 & 600 & 0.034 \\
\hline
\end{tabular}

Table 3. Elastic constants

\begin{tabular}{lccccc}
\hline $\begin{array}{l}\text { Case } \\
\text { No. }\end{array}$ & $\begin{array}{c}\text { Bulk } \\
\text { density } \\
\left(\mathrm{kN} \mathrm{m}^{-3}\right)\end{array}$ & $\begin{array}{c}\text { Maximum } \\
\text { loading } \\
\text { stress } \\
(\mathrm{kPa})\end{array}$ & $\begin{array}{c}\text { Average } \\
E^{*} \\
(\mathrm{MPa})\end{array}$ & $\begin{array}{c}\text { Poisson } \\
\text { ratio v }\end{array}$ & $\begin{array}{c}\text { Average } \\
E(\mathrm{MPa})\end{array}$ \\
\hline $\mathrm{T}-1$ & 8.27 & 100 & 28.2 & 0.20 & 25.4 \\
$\mathrm{~T}-2$ & 8.27 & 200 & 27.2 & 0.20 & 26.3 \\
$\mathrm{~T}-3$ & 8.27 & 400 & 39.4 & 0.20 & 35.5 \\
$\mathrm{~T}-4$ & $8.27-8.74$ & 600 & 49.5 & 0.20 & 44.6 \\
$\mathrm{~T}-5$ & 8.27 & 600 & 48.2 & 0.20 & 43.4 \\
\hline
\end{tabular}

occurred during the first loading. While in the tenth cycle, the compression index had the smallest value, which is 0.034 . For different maximum loading stress values and different bulk density values (case T-1 to T-4), the average value of the compression index ranges from 0.099 to 0.197 . No obvious differences can be found, as shown by the results.

Elastic constants were determined using Eq. (8) with experimental results at the first stage of unloading, which may reflect elastic deformation without particle deformation occurring. According to Eq. (8), the compression modulus $E^{*}$ and Poisson's ratio are required to calculate the value of the elastic modulus, these parameters were evaluated from the experimental results. $E^{*}$ may be derived from the slope of sector $\mathrm{AB}$ as described above. Poisson's ratio was assumed to be 0.20 , which was also recommended by Sawicki et al. (1998). The modulus of elasticity of wheat ranged from 25.4 to $44.6 \mathrm{MPa}$ for different compression stresses and bulk densities in the present study (Table 3). It was observed, that there were some variations between the different tests. This variation was probably due to the distinctly different maximum stresses. The values of the modulus of elasticity for wheat reported by various researchers ranged widely form 0.7 to $70 \mathrm{MPa}$ (Sawicki and Świdziński 1998; Molenda et al., 2006; Stasiak et al., 2007; Moya et al., 2013). The variation in the results was probably due to the differences in the experiment material itself, the test apparatus, test methods and the levels of applied pressure.

\section{CONCLUSIONS}

The confined uniaxial compression tests were performed on the granular wheat. The compression characteristics of the granular wheat were investigated based on the experimental results. A series of loading and unloading tests were conducted on the granular wheat. The modulus of elasticity was also estimated based on the stress-strain curves. The conclusions based on the present study are summarized as follows:

1. The values of the compression index were determined. The effect of the maximum loading stress was analysed. The results indicated that the parameter ranged from 0.034 to 0.197 , with a mean value of 0.08 for the test wheat.

2. Because the material is rapidly compacted in the initial cycle, the compaction curve is steeper and nearly $80 \%$ of the total deformation occurred at the initial loading stage.

3. Values of the modulus of elasticity were determined in uniaxial compression tests. The first stage of unloading corresponds to the elastic response of the material. Values of the modulus of elasticity ranged from 25.4 to $44.6 \mathrm{MPa}$. The modulus of elasticity of wheat was variable according to the different maximum stress applied.

Conflict of interest: The Authors do not declare conflict of interest.

\section{REFERENCES}

Akbas S.O. and Kulhawy F.H., 2009. Axial compression of footings in cohesionless soils. I: Load-settlement behavior. J. Geotechnical Geoenvironmental Eng., 135(11), 15621574. https://doi.org/10.1061/(asce)gt.1943-5606.0000135

An J., Zhang Y., and Yu N., 2015. Quantifying the effect of soil physical properties on the compressive characteristics of two arable soils using uniaxial compression tests. Soil Till. Res., 145, 216-223. https://doi.org/10.1016/j. still.2014.09.002

Arvidsson J. and Keller T., 2004. Soil precompression stress: I. A survey of Swedish arable soils. Soil Till. Res., 77: 85-95. https://doi.org/10.1016/j.still.2004.01.003

Boac J.M., Bhadra R., Casada M.E., Thompson S.A., Turner A.P., Montross M.D., ... and Maghirang R.G., 2015. Stored grain pack factors for wheat: Comparison of three methods to field measurements. Transactions of the ASABE, 58(4), 1089-1101. https://doi.org/10.13031/trans.58.10898 
Cetin H., 2004. Soil-particle and pore orientations during consolidation of cohesive soils. Engineering Geology, 73(1-2), 1-11. https://doi.org/10.1016/j.enggeo.2003.11.006

Fitzpatrick J.J., Barringer S.A., and Iqbal T., 2004. Flow property measurement of food powders and sensitivity of Jenike's hopper design methodology to the measured values. J. Food Eng., 61(3), 399-405. https://doi.org/10.1016/ s0260-8774(03)00147-x

Gao M., Cheng X., and Du X., 2018. Simulation of bulk density distribution of wheat in silos by finite element analysis.J. Stored Products Res., 77, 1-8. https://doi.org/10.1016/j. jspr.2018.02.003

Gregory A.S., Whalley W.R., Watts C.W., Bird N.R.A., Hallett P.D., and Whitmore A.P., 2006. Calculation of the compression index and precompression stress from soil compression test data. Soil Till. Res., 89(1), 45-57. https:// doi.org/10.1016/j.still.2005.06.012

Horabik J. and Molenda M., 2014. Mechanical properties of granular materials and their impact on load distribution in silo: a review. Scientia Agriculturae Bohemica, 45(4), 203211. https://doi.org/10.1515/sab-2015-0001

Horabik J. and Rusinek R., 2002. Pressure ratio of cereal grains determined in a uniaxial compression test. Int. Agrophysics, 16(1), 23-28.

Jiang M.J., Li T., Hu H.J., and Thornton C., 2014. DEM analyses of one-dimensional compression and collapse behaviour of unsaturated structural loess. Computers Geotechnics, 60, 47-60. https://doi.org/10.1016/j. compgeo.2014.04.002

Keller T., Lamandé M., Schjønning P., and Dexter A.R., 2011. Analysis of soil compression curves from uniaxial confined compression tests. Geoderma, 163(1-2), 13-23. https://doi. org/10.1016/j.geoderma.2011.02.006

Li X., Cao Z., Wei Z., Feng Q., and Wang J., 2011. Equilibrium moisture content and sorption isosteric heats of five wheat varieties in China. Journal of Stored Products Research, 47(1), 39-47. https://doi.org/10.1016/j.jspr.2010.10.001

Liu S.D., Zhou Z.Y., Zou R.P., Pinson D., and Yu A.B., 2014. Flow characteristics and discharge rate of ellipsoidal particles in a flat bottom hopper. Powder Technol., 253, 70-79. https://doi.org/10.1016/j.powtec.2013.11.001

Madiouli J., Sghaier J., Lecomte D., and Sammouda H., 2012. Determination of porosity change from shrinkage curves during drying of food material. Food Bioproducts Proc., 90(1), 43-51. https://doi.org/10.1016/j.fbp.2010.12.002

Mohammadzadeh D., Bazaz J.B., and Alavi A.H., 2014. An evolutionary computational approach for formulation of compression index of fine-grained soils. Eng. Appl. Artificial Intelligence, 33, 58-68. https://doi.org/10.1016/j. engappai.2014.03.012

Molenda M. and Stasiak M., 2002. Determination of the elastic constants of cereal grains in a uniaxial compression test. Int. Agrophysics, 16(1), 61-66.

Molenda M., Stasiak M., Moya M., Ramirez A., Horabik J., and Ayuga F., 2006. Testing mechanical properties of food powders in two laboratories-degree of consistency of results. Int. Agrophysics, 20(1), 37-45.

Monkul M.M. and Önal O., 2006. A visual basic program for analyzing oedometer test results and evaluating intergranular void ratio. Computer and Geoscience, 32, 696-703. https://doi.org/10.1016/j.cageo.2005.09.005
Moya M., Aguado P.J., and Ayuga F., 2013. Mechanical properties of some granular agricultural materials used in silo design. Int. Agrophys., 27(2), 181-193. https://doi. org/10.2478/v10247-012-0084-9

Moya M., Ayuga F., Guaita M., and Aguado P., 2002. Mechanical properties of granular agricultural materials. Trans. ASAE, 45(5), 1569-1577. https://doi. org/10.13031/2013.11062

Moya M., Guaita M., Aguado P., and Ayuga F., 2006. Mechanical properties of granular agricultural materials, part 2. Trans. ASABE, 49(2), 479-489. https://doi. org/10.13031/2013.20403

Ortiz R., Sayre K.D., Govaerts B., Gupta R., Subbarao G.V., Ban T., ... and Reynolds M., 2008. Climate change: can wheat beat the heat? Agriculture, Ecosystems Environment, 126(1-2), 46-58. https://doi.org/10.1016/j.agee.2008.01.019

Ramírez A., Moya M., and Ayuga F., 2009. Determination of the mechanical properties of powdered agricultural products and sugar. Particle and Particle Systems Characterization, 26(4), 220-230. https://doi.org/10.1002/ppsc.200800016

Ramírez A., Nielsen J., and Ayuga F., 2010. Pressure measurements in steel silos with eccentric hoppers. Powder Technol., 201(1), 7-20. https://doi.org/10.1016/j. powtec.2010.02.027

Sawicki A. and Świdziński W., 1998. Elastic moduli of non-cohesive particulate materials. Powder Technol., 96(1), 24-32. https://doi.org/10.1016/s0032-5910(97)03354-8

Stasiak M., 2003. Determination of elastic parameters of grain with oedometric and acoustic methods. Res. Agric. Eng., 49, 56-60. https://doi.org/10.17221/4953-rae

Stasiak M., Molenda M., and Horabik J., 2007. Determination of modulus of elasticity of cereals and rapeseeds using acoustic method. J. Food Eng., 82(1), 51-57. https://doi. org/10.1016/j.jfoodeng.2007.01.017

Stasiak M., Tomas J., Molenda M., Rusinek R., and Mueller P., 2010. Uniaxial compaction behaviour and elasticity of cohesive powders. Powder Technol., 203(3), 482-488. https://doi.org/10.1016/j.powtec.2010.06.010

Thompson S.A. and Ross I.J., 1983. Compressibility and frictional coefficients of wheat. Trans. ASAE, 26(4), 1171-1176. https://doi.org/10.13031/2013.34099

Trade Standard of P.R. China SL237, 1999. Specification of soil test (in Chinese). The Ministry of Water Resources of P.R. China, Beijing, China.

Turner A.P., Montross M.D., McNeill S.G., Sama M.P., Casada M.C., Boac J.M., ... and Thompson S.A., 2016. Modeling the compressibility behavior of hard red wheat varieties. Transactions of the ASABE, 59(3), 1029-1038. https://doi. org/10.13031/trans.59.11432

Wang J.J., Qiu Z.F., Hao J.Y., and Zhang J.T., 2016. Compression characteristics of an artificially mixed soil from confined uniaxial compression tests. Environ. Earth Sci., $\quad 75(2), \quad 152 . \quad$ https://doi.org/10.1007/ s12665-015-5042-y

Wang Y., Gao Y., Guo L., and Yang Z., 2018. Influence of intermediate principal stress and principal stress direction on drained behavior of natural soft clay. Int. J. Geomechanics, 18(1), $\quad 04017128 . \quad$ https://doi.org/10.1061/(asce) gm.1943-5622.0001042

Wang Y., Gao Y., Li B., Guo L., Cai Y., and Mahfouz A.H., 2019. Influence of initial state and intermediate principal stress on 
undrained behavior of soft clay during pure principal stress rotation. Acta Geotechnica, 1-23. https://doi.org/10.1007/ s11440-018-0735-5

Xiao Y., Liu H., Chen Q., Long L., and Xiang J., 2017. Evolution of particle breakage and volumetric deformation of binary granular soils under impact load. Granular Matter, 19(4), 71. https://doi.org/10.1007/s10035-017-0756-z

Yigit E., 2018. A novel compressed sensing based quantity measurement method for grain silos. Computers and Electronics in Agriculture, 145, 179-186. https://doi.org/10.1016/j. compag.2017.12.041
Zhang S., Lin P., Wang C.L., Tian Y., Wan J.F., and Yang L., 2014. Investigating the influence of wall frictions on hopper flows. Granular Matter, 16(6), 857-866. https://doi. org/10.1007/s10035-014-0533-1

Zhang Q. and Britton M.G., 2003. A micromechanics model for predicting dynamic loads during discharge in bulk solids storage structures. Canadian Biosys. Eng., 45, 5.21-5.27.

Zhao Y., Cao Q.S., and Su L., 2013. Buckling design of large circular steel silos subject to wind pressure. Thin-Walled Structures, 73, 337-349. https://doi.org/10.1016/j. tws.2013.08.015 